\title{
Nanosponges: A Novel Class of Drug Delivery System - Review
}

\author{
Selvamuthukumar Subramanian, Anandam Singireddy, Kannan Krishnamoorthy and Manavalan Rajappan \\ Department of Pharmacy, Faculty of Engineering and Technology, Annamalai University, Annamalai Nagar, Tamil \\ Nadu, India.
}

Received, January 6, 2012; Revised, January 9, 2012; Accepted, January 11, 2012; Published, January 12, 2012.

\begin{abstract}
Effective targeted drug delivery systems have been a dream for a long time, but it has been largely frustrated by the complex chemistry that is involved in the development of new systems. The invention of nanosponges has become a significant step toward overcoming these problems. Nanosponges are tiny sponges with a size of about a virus, which can be filled with a wide variety of drugs. These tiny sponges can circulate around the body until they encounter the specific target site and stick on the surface and begin to release the drug in a controlled and predictable manner. Because the drug can be released at the specific target site instead of circulating throughout the body it will be more effective for a particular given dosage. Another important character of these sponges is their aqueous solubility; this allows the use of these systems effectively for drugs with poor solubility.

This article is open to POST-PUBLICATION REVIEW. Registered readers (see "For Readers") may comment by clicking on ABSTRACT on the issue's contents page.
\end{abstract}

\section{INTRODUCTION}

Targeting the delivery of drugs has long been a problem for medical researchers - how to get them to the right place in the body and how to control the release of the drug to prevent overdoses. The developments of new and complex molecules called nanosponges have the potential to solve these problems.

Nanosponges are a new class of materials and made of microscopic particles with few nanometers wide cavities, in which a large variety of substances can be encapsulated. These particles are capable of carrying both lipophilic and hydrophilic substances and of improving the solubility of poorly water soluble molecules (1). Nanosponges are tiny mesh-like structures that may revolutionise the treatment of many diseases and early trials suggest this technology is up to five times more effective at delivering drugs for breast cancer than conventional methods (2).

The nanosponge is about the size of a virus with a 'backbone' (a scaffold structure) of naturally degradable polyester. The long length polyester strands are mixed in solution with small molecules called cross-linkers that have an affinity for certain portions of the polyester. They 'cross link' segments of the polyester to form a spherical shape that has many pockets (or cavities) where drugs can be stored. The polyester is predictably biodegradable, which means that when it breaks up in the body, the drug can be released on a known schedule (2).

The nanosponges are encapsulating type of nanoparticles which encapsulates the drug molecules within its core. By the method of associating with drugs, the nanoparticles can be classified into encapsulating nanoparticles, complexing nanoparticles and conjugating nanoparticles. The first type is represented by nanosponges and nanocapsules. Nanosponges such as alginate nanosponge, which are spongelike nanoparticles containing many holes that carry the drug molecules. Nanocapsules such as poly(isobutyl-cyanoacrylate) (IBCA) are also encapsulating nanoparticles. They can entrap drug molecules in their aqueous core. The second category is Complexing nanoparticle, which attracts the molecules by electrostatic charges. The third type is Conjugating nanoparticle, which links to drugs through covalent bonds (3).

These nanosponges represent a novel class of nanoparticles usually obtained by natural derivatives. As compared to the other nanoparticles, they are insoluble both in water and organic solvents, porous, non toxic and stable at high temperatures up to $300^{\circ} \mathrm{C}$.

\footnotetext{
Corresponding Author: Selvamuthukumar Subramanian, Assistant Professor, Department of Pharmacy, Faculty of Engineering and Technology, Annamalai University, Annamalai Nagar, Tamil Nadu, India-608002, Email: smk1976@gmail.com
} 
They are able to capture, transport and selectively release a huge variety of substances because of their 3D structure containing cavities of nanometric size and tunable polarity. Furthermore, nanosponges show a remarkable advantage in comparison with the common nanoparticles: indeed, they can be easily regenerated by different treatments, such as washing with eco-compatible solvents, stripping with moderately inert hot gases, mild heating, or changing $\mathrm{pH}$ or ionic strength. For all these characteristics, nanosponges have been already employed in different applied fields, such as cosmetic and pharmaceutical sectors (4).

Nanosponges can be used as a vessel for pharmaceutical principles to improve aqueous solubility of lipophilic drugs, to protect degradable molecules and to formulate drug delivery systems for various administration routes besides the oral one. The simple chemistry of polymers and cross linkers does not pose many problems in the preparation and this technology can be easily ramp up to commercial production levels. Nanosponges are water soluble but does not breakup chemically in water. They mix with water and use as a transport fluid. They can be used to mask unpleasant flavours, to convert liquid substances to solids. The chemical linkers enable the nanosponges to bind preferentially to the target site.

The main disadvantage of these nanosponges is their ability to include only small molecules. The nanosponges could be either paracrystalline or in crystalline form. The loading capacity of nanosponges depends mainly on degree of crystallisation. Paracrystalline nanosponges can show different loading capacities.

The nanosponges can be synthesized to be of specific size and to release drugs over time by varying the proportion of cross linker to polymer. The engineering capacity of nanosponge is due to the relatively simple chemistry of its polyesters and cross-linking peptides, compared to many other nanoscale drug delivery systems (2). These nanosponges can be magnetized when they are prepared in the presence of compounds having magnetic properties (5). The tiny shape of nanosponges enables the pulmonary and venous delivery of nanosponges (1).

The list of polymers and crosslinking agents used for the synthesis of nanosponges are presented in Table-1.

\section{APPLICATIONS OF NANOSPONGES:}

\section{Nanosponges for drug delivery}

Because of their nanoporous structure, nanosponges can advantageously carry waterinsoluble drugs (Biopharmaceutical Classification System class-II drugs). These complexes can be used to increase the dissolution rate, solubility and stability of drugs, to mask unpleasant flavors and to convert liquid substances to solids. $\beta$ Cyclodextrin based nanosponges are reported to deliver the drug to the target site three to five times more effectively than direct injection (2).

Drugs which are particularly critical for formulation in terms of their solubility can be successfully delivered by loading into the nanosponges. List of some BCS Class II dugs which can be developed as nanosponges are given in Table 2.

The nanosponges are solid in nature and can be formulated as Oral, Parenteral, Topical or Inhalation dosage forms. For the oral administration, the complexes may be dispersed in a matrix of excipients, diluents, lubricants and anticaking agents suitable for the preparation of capsules or tablets (5). For the parenteral administration the complex may be simply carried in sterile water, saline or other aqueous solutions (5). For topical administration they can be effectively incorporated into topical hydrogel $(7,8)$. The nanosponges used in the formulation of some drugs are provided in the Table 3.

Nanosponges as a carrier for biocatalysts and in the delivery and release of enzymes, proteins, vaccines and antibodies

Many industrial processes involving chemical transformation are associated with operational disadvantages. Non-specific reactions lead to low yields, and the frequent need to operate at high temperatures and pressures requires consumption of large amounts of energy, and very large amounts of cooling water in the down-stream process. All these drawbacks can be eliminated or significantly reduced by using enzymes as biocatalysts. These enzymes operate under mild reaction conditions, have high reaction speed, and are highly specific. They have a beneficial effect on the environment because they reduce energy consumption and reduce production of pollutants. The catalytic activity of enzyme depends mainly on the correct orientation of the active site (18).

Proteins, peptides, enzymes and derivatives thereof also can be used in the biomedical and therapeutic field. Proteolytic enzymes can be used 
to treat cancer or type I mucopolysaccharidosis, while DNA and oligonucleotides are used in gene therapy. The administration of these molecules present various problems and limitations. Most protein drugs are poorly absorbed through the biological membranes due to the some factors such as large molecular size, hydrophilic nature, degree of ionization, high surface charge, chemical and enzymatic instability and low permeability through mucous membranes. Following intravenous administration, protein molecules may be rapidly cleared from blood, bind to plasma proteins, and sensitive towards proteolytic enzymes. With oral administration bioavailability is the problem. Various approaches exist for therapeutic use, such as increasing the dose or using absorption promoters, which can cause toxicity problems (18).
A number of systems for carrying enzymes and proteins have been developed, such as nano and microparticles, liposomes and hydrogels. Carriage in a particular system can protect proteins from breakdown, modify their pharmacokinetics and improve their stability invivo. Now, it has been found that Cyclodextrin based nanosponges are particularly suitable carrier to adsorb proteins, enzymes, antibodies and macromolecules. In particular when enzymes are used, it is possible to maintain their activity, efficiency, prolong their operation and extends the $\mathrm{pH}$ and temperature range of activity and allows the conduct of continuous flow processes. Moreover, proteins and other macromoleculs can be carried by adsorbing or encapsulating them in cyclodextrin nanosponges (18).

\begin{tabular}{ll}
\hline Table 1. Chemicals used for the synthesis of nanosponges \\
\hline Polymers & $\begin{array}{l}\text { Hyper cross linked Polystyrenes, Cyclodextrines and its derivatives like Methyl } \beta \text {-Cyclodextrin, } \\
\text { Alkyloxycarbonyl Cyclodextrins, 2-Hydroxy Propyl } \beta \text {-Cyclodextrins and }\end{array}$ \\
& $\begin{array}{l}\text { Copolymers like Poly(valerolactone-allylvalerolactone) \& Poly(valerolactone-allylvalerolactone- } \\
\text { oxepanedione) and Ethyl Cellulose \& PVA }\end{array}$ \\
Crosslinkers & $\begin{array}{l}\text { Diphenyl Carbonate, Diarylcarbonates, Diisocyanates, Pyromellitic anhydride, } \\
\text { Carbonyldiimidazoles, Epichloridrine, Glutarldehyde, Carboxylic acid dianhydrides, 2,2- } \\
\text { bis(acrylamido) Acetic acid and Dichloromethane }\end{array}$ \\
\hline
\end{tabular}

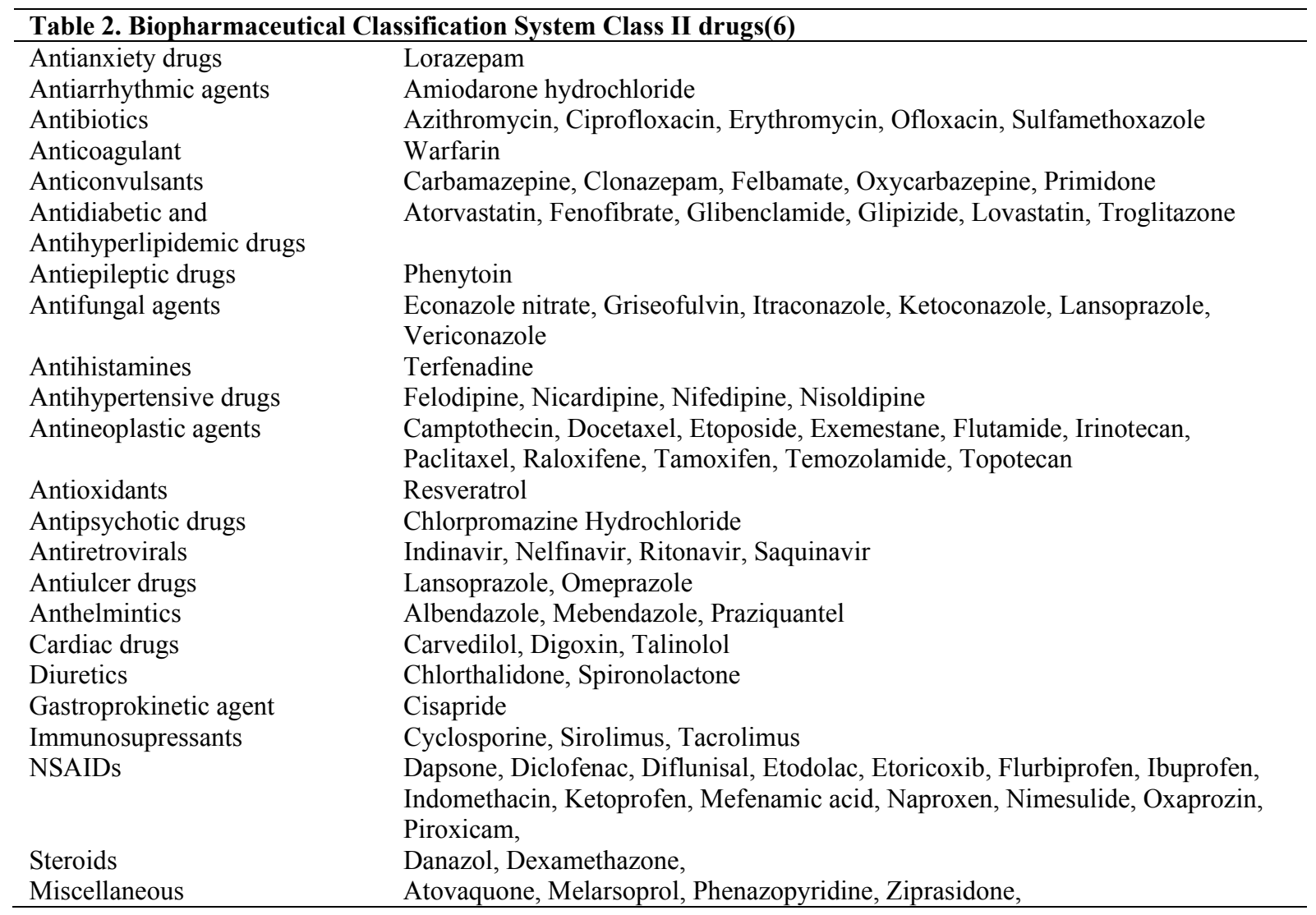




\begin{tabular}{|c|c|c|c|c|c|}
\hline \multicolumn{6}{|c|}{ Table 3. Examples of nanosponges } \\
\hline Drug & Nanosponge vehicle & Indication & Study & $\begin{array}{c}\text { In vitro / in vivo } \\
\text { / Mathematical } \\
\text { model }\end{array}$ & Reference \\
\hline \multirow[t]{3}{*}{ Paclitaxel } & \multirow[t]{3}{*}{$\beta$-cyclodextrin } & \multirow[t]{3}{*}{ Cancer } & Bio- availability & Sprague & 9 \\
\hline & & & & Dawley rats & \\
\hline & & & Cytotoxicty & MCF7 cell line & 10 \\
\hline \multirow[t]{2}{*}{ Camptothecin } & \multirow[t]{2}{*}{$\beta$-Cyclodextrin } & \multirow[t]{2}{*}{ Cancer } & Haemolytic activity & Diluted blood & \\
\hline & & & Cytotoxicty & HT-29 cell line & 11,12 \\
\hline Tamoxifen & $\beta$-Cyclodextrin & Breast cancer & Cytotoxicty & $\mathrm{MCF}-7$ cell line & 5 \\
\hline \multirow[t]{4}{*}{ Resveratrol } & \multirow[t]{4}{*}{$\beta$-Cyclodextrin } & \multirow{4}{*}{$\begin{array}{l}\text { Inflammation, } \\
\text { Cardiovascular } \\
\text { diseases, Dermatitis, } \\
\text { Gonorrhea, } \\
\text { Fever and } \\
\text { Hyperlipidemia }\end{array}$} & Cytotoxicty & HCPC-I cell line & \multirow[t]{4}{*}{13} \\
\hline & & & $\begin{array}{l}\text { Accumulation of } \\
\text { drug in the buccal } \\
\text { mucosa of rabbit }\end{array}$ & $\begin{array}{l}\text { Rabbit buccal } \\
\text { mucosa }\end{array}$ & \\
\hline & & & Ex-Vivo Study & & \\
\hline & & & Permeation study & Pig skin & \\
\hline Temozolamide & $\begin{array}{l}\text { Poly (valerolactone- } \\
\text { allylvalerolactone) and } \\
\text { poly } \\
\text { (valerolactone- } \\
\text { allylvalerolactone - } \\
\text { oxepanedione) }\end{array}$ & Brain tumors & Drug release study & $\begin{array}{l}\text { In vitro and in } \\
\text { vivo studies }\end{array}$ & 14 \\
\hline Econazole nitrate & $\begin{array}{l}\text { Ethyl cellulose } \\
\text { Polyvinyl alcohol }\end{array}$ & Antifungal & Irritation study & Rat & 7,8 \\
\hline Itraconazole & $\begin{array}{l}\beta \text {-Cyclodextrin \& } \\
\text { copolyvidonum }\end{array}$ & Antifungal & $\begin{array}{l}\text { Saturation solubility } \\
\text { study }\end{array}$ & Higuchi Model & 15 \\
\hline Dexamethasone & $\beta$-Cyclodextrin & Brain tumors & $\begin{array}{l}\text { Drug release } \\
\text { experiment }\end{array}$ & $\begin{array}{l}\text { Dialysis bag } \\
\text { technique in } \\
\text { vitro }\end{array}$ & 16 \\
\hline \multirow{2}{*}{$\begin{array}{l}\text { Antisense } \\
\text { oligonucleotides }\end{array}$} & \multirow{2}{*}{$\begin{array}{l}\text { Sodium alginate } \\
\text { Poly L-lysine }\end{array}$} & Cancer therapy & \multirow{2}{*}{$\begin{array}{l}\text { Pharmacokinetic } \\
\text { studies }\end{array}$} & \multirow[t]{2}{*}{ Mice } & \multirow[t]{2}{*}{17} \\
\hline & & $\begin{array}{l}\text { Viral infections } \\
\text { Pathologic disorders }\end{array}$ & & & \\
\hline
\end{tabular}

\section{Other applications of Nanosponges}

Nanosponges based on cyclodextrins can strongly bind organic molecules and remove them from water even at very low concentrations (19). The same concept can be useful for elimination of bitter components from grape fruit juice by selective combination of polymer and crosslinker. The microporous hyper cross linked nanosponges have been used in selective separation of inorganic electrolytes by size exclusion chromatography. The three dimensional nanosponges will play important role in the fractionalization of peptides for proteomic applications (20). Nanosponges can be used as carrier for gases like oxygen and carbon dioxide. These nanosponges could be useful for many biomedical applications. In particular the oxygen-filled nanosponges could supply oxygen to the hypoxic tissues which are present in various deseases (21). Nanosponges can selectively soak up biomarkers for the diagnosis. One study concluded that nanosponges can harvest rare cancer marker from blood (22).

\section{SYNTHESIS OF NANOSPONGES}

\section{Solvent method}

Mix the polymer with a suitable solvent, in particular in a polar aprotic solvent such as dimethylformamide, dimethylsulfoxide. Then add this mixture to excess quantity of the cross-linker, preferably in crosslinker/polymer molar ratio of 4 to 16. Carry out the reaction at temperature ranging from $10^{\circ} \mathrm{C}$ to the reflux temperature of the solvent, for time ranging from 1 to $48 \mathrm{~h}$. Preferred crosslinkers are carbonyl compounds (Dimethyl carbonate \& Carbonyldiimidazole) (5).

After completion of the reaction, allow the solution to cool at room temperature, then add the product to large excess of bidistilled water and recover the product by filtration under vacuum and subsequently purify by prolonged soxhlet 
extraction with ethanol. Dry the product under vacuum and grind in a mechanical mill to obtain homogeneous powder (16).

\section{Ultarsound-Assisted synthesis}

In this method nanosponges can be obtained by reacting polymers with cross-linkers in the absence of solvent and under sonication. The nanosponges obtained by this method will be spherical and uniform in size (1).

Mix the polymer and the cross-linker in a particular molar ratio in a flask. Place the flask in an ultrasound bath filled with water and heat it to $90^{\circ} \mathrm{C}$. Sonicate the mixture for 5hours. Then allow the mixture to cool and break the product roughly. Wash the product with water to remove the nonreacted polymer and subsequently purify by prolonged soxhlet extraction with ethanol. Dry the obtained product under vacuum and store at $25^{\circ} \mathrm{C}$ until further use $(1,16)$.

\section{Loading of drug into nanosponges}

Nanosponges for drug delivery should be pretreated to obtain a mean particle size below $500 \mathrm{~nm}$. Suspend the nanosponges in water and sonicate to avoid the presence of aggregates and then centrifuge the suspension to obtain the colloidal fraction. Separate the supernatant and dry the sample by freeze drying (16).

Prepare the aqueous suspension of Nanosponge and disperse the excess amount of the drug and maintain the suspension under constant stirring for specific time required for complexation. After complexation, separate the uncomplexed (undissolved) drug from complexed drug by centrifugation. Then obtain the solid crystals of nanosponges by solvent evaporation or by freeze drying $(5,16)$.

Crystal structure of nanosponge plays a very important role in complexation with drug. A study revealed that paracrystalline nanosponges showed different loading capacities when compared to crystalline nanosponges. The drug loading is greater in crystalline nanosponges than paracrystalline one. In poorly crystalline nanosponges, the drug loading occurs as a mechanical mixture rather than inclusion complex (11).

\section{FACTORS INFLUENCE NANOSPONGE FORMATION}

Type of polymer

Type of polymer used can influence the formation as well as the performance of Nanosponges. For complexation, the cavity size of nanosponge should be suitable to accommodate a drug molecule of particular size.

\section{Type of drugs}

Drug molecules to be complexed with nanosponges should have certain characteristics mentioned below (23).

- Molecular weight between 100 and 400

- Drug molecule consists of less than five condensed rings

- Solubility in water is less than $10 \mathrm{mg} / \mathrm{mL}$

- Melting point of the substance is below $250^{\circ} \mathrm{C}$

\section{Temperature}

Temperature changes can affect Drug/Nanosponge complexation. In general, increasing in the temperature decreases the magnitude of the apparent stability constant of the Drug/Nanosponge complex may be due to a result of possible reduction of drug/nanosponge interaction forces, such as van-der Waal forces and hydrophobic forces with rise of temperature (24).

\section{Method of preparation}

The method of loading the drug into the nanosponge can affect Drug/Nanosponge complexation. However, the effectiveness of a method depends on the nature of the drug and polymer, in many cases freeze drying was found to be most effective for drug complexation (24).

\section{Degree of substitution}

The complexation ability of the nanosponge may be greatly affected by type, number and position of the substituent on the parent molecule (24).

\section{CHARACTERIZATION OF NANO- SPONGES}

Inclusion complexes formed between the drug and nanosponges can be characterized by following methods.

\section{Thermo-analytical methods}

Thermo-analytical methods determine whether the drug substance undergoes some change before the thermal degradation of the nanosponge. The change of the drug substance may be melting, evaporation, decomposition, oxidation or polymorphic transition. The change of the drug substance indicates the complex formation. The 
thermogram obtained by DTA and DSC can be observed for broadening, shifting and appearance of new peaks or disappearance of certain peaks. Changes in the weight loss also can provide supporting evidence for the formation of inclusion complexes (25).

\section{Microscopy studies}

Scanning Electron Microscopy (SEM) and Transmission Electron Microscopy (TEM) can be used to study the microscopic aspects of the drug, nanosponges and the product (drug/nanosponge complex). The difference in crystallization state of the raw materials and the product seen under electron microscope indicates the formation of the inclusion complexes $(11,25)$.

\section{X-ray diffractiometry and single crystal X-ray structure analysis}

Powder X-ray diffractiometry can be used to detect inclusion complexation in the solid state. When the drug molecule is liquid since liquid have no diffraction pattern of their own, then the diffraction pattern of a newly formed substance clearly differs from that of uncomplexed nanosponge. This difference of diffraction pattern indicates the complex formation. When the drug compound is a solid substance, a comparison has to be made between the diffractogram of the assumed complex and that of the mechanical mixture of the drug and polymer molecules (25).

A diffraction pattern of a physical mixture is often the sum of those of each component, while the diffraction pattern of complexes are apparently different from each constituent and lead to a "new" solid phase with different diffractograms. Diffraction peaks for a mixture of compounds are useful in determining the chemical decomposition and complex formation (25).

The complex formation of drug with nanosponges alters the diffraction patterns and also changes the crystalline nature of the drug. The complex formation leads to the sharpening of the existing peaks, appearance of a few new peaks and shifting of certain peaks (25).

Single crystal X-ray structure analysis may be used to determine the detailed inclusion structure and mode of interaction. The interaction between the host and guest molecules can be identified and the precise geometrical relationship can be established (25).

\section{Solubility studies}

The most widely used approach to study inclusion complexation is the phase solubility method described by Higuchi and Connors, which examines the effect of a nanosponge, on the solubility of drug. Phase solubility diagrams indicate the degree of complexation $(5,24)$.

\section{Infra-Red spectroscopy}

Infra-Red spectroscopy is used to estimate the interaction between nanosponges and the drug molecules in the solid state.

Nanosponge bands often change only slightly upon complex formation and if the fraction of the guest molecules encapsulated in the complex is less than $25 \%$, bands which could be assigned to the included part of the guest molecules are easily masked by the bands of the spectrum of nanosponges. The technique is not generally suitable to detect the inclusion complexes and is less clarifying than other methods (25).

The application of the Infra-red spectroscopy is limited to the drugs having some characteristic bands, such as carbonyl or sulfonyl groups. Infrared spectral studies give information regarding the involvement of hydrogen in various functional groups. This generally shifts the absorbance bands to the lower frequency, increases the intensity and widens the band caused by stretching vibration of the group involved in the formation of the hydrogen bonds. Hydrogen bond at the hydroxyl group causes the largest shift of the stretching vibration band (25).

\section{Thin Layer Chromatography}

In Thin Layer Chromatography, the Rf values of a drug molecule diminishes to considerable extent and this helps in identifying the complex formation between the drug and nanosponge (25).

\section{Loading efficiency}

The loading efficiency of nanosponges can be determined by the quantitative estimation of drug loaded into nanosponges by UV spectrophotometer \& HPLC methods.

\section{Particle size and polydispersity}

The particle size can be determined by dynamic light scattering using 90 Plus particle sizer equipped with MAS OPTION particle sizing software. From this the mean diameter and polydispersity index can be determined (11). 


\section{Zeta potential}

Zeta potential is a measure of surface charge. It can be measured by using additional electrode in the particle size equipment (11).

\section{CONCLUSION}

The nanosponges have the ability to include either lipophilic or hydrophilic drugs and release them in a controlled and predictable manner at the target site. By controlling the ratio of polymer to the cross-linker the particle size and release rate can be modulated. Nanosponges enable the insoluble drugs and protect the active moieties from physicochemical degradation and controlled release. Because of their small size and spherical shape nanosponges can be developed as different dosage forms like parenteral, aerosol, topical, tablets and capsules.

\section{REFERENCES}

1. Trotta F, Cavalli R, Tumiatti W, Zerbinati O, Rogero C, Vallero R. Ultrasound-assisted synthesis of Cyclodextrin-based nanosponges. EP 1786841 B1; 2007.

2. David F. Nanosponge drug delivery system more effective than direct injection. www.physorg.com 01.06.2010, accessed on 20.12.2011.

3. Trotta F, Tumiatti V, Cavalli R, Rogero C, Mognetti B, Berta G. Cyclodextrin-based nanosponges as a vehicle for Antitumoral drugs. WO 2009/003656 A1; 2009.

4. Liang L, De-Pei L, Chih-Chuan L. Optimizing the delivery systems of chimeric RNA . DNA oligonucleotides beyond general oligonucleotide transfer. Eur. J. Biochem. 2002; 269: 5753-5758.

5. Jenny A, Merima P, Alberto F, Francesco T. Role of $\beta$ - cyclodextrin nanosponges in polypropylene photooxidation. Carbohydrate Polymers, 2011; 86: $127-135$.

6. Leslie Z. Benet., BCS and BDDCS. Bioavailability and Bioequivalence: Focus on Physiological Factors and Variability. Department of biopharmaceutical sciences, University of California, San Francisco, USA, 2007.

7. Renuka S, Roderick BW, Kamla P. Evaluation of the kinetics and mechanism of drug release from Econazole Nitrate nanosponge loaded carbapol hydrogel. Ind J Parm Edu Res, 2011; 45(1): 2531.

8. Renuka S, Kamla P. Polymeric nanosponges as an alternative carrier for improved retention of econazole nitrate onto the skin through topical hydrogel Pharm Dev Technol. 2011; 16(4):367-376.
9. Torne SJ, Ansari KA, Vavia PR, Trotta F, Cavalli R. Enhanced oral Paclitaxel bioavailability after administration of Paclitaxel loaded nanosponges. Drug Delivery, 2010; 17(6):419-425.

10. Ansari KA, Torne SJ, Vavia PR, Trotta F, Cavalli R. Paclitaxel loaded nanosponges: in-vitro characterization and cytotoxicity study on MCF-7 cell line culture. Curr Drug Deliv, 2011; 8(2):194202.

11. Shankar S, Linda P, Loredana S, Francesco T, Pradeep V, Dino A, Michele T, Gianpaolo Z, Roberta C. Cyclodextrin-based nanosponges encapsulating camptothecin: Physicochemical characterization, stability and cytotoxicity. Eur J Pharm Biopharm, 2010; 74: 193-201.

12. Rosalba M, Roberta C, Roberto F, Chiara D, Piergiorgio P, Leigh E, Li S, Roberto P. Antitumor activity of nanosponge-encapsulated Camptotechin in human prostate tumors. Cancer Res, 2011; 71:4431

13. Khalid AA, Pradeep RV, Francesco T, Roberta C. Cyclodextrin-based nanosponges for delivery of Resveratrol: In Vitro characterisation, stability, cytotoxicity and permeation Study AAPS PharmSciTech, 2011; 12(1): 279-286.

14. William K, Benjamin S, Eva H. Synthesis and Characterization of Nanosponges for Drug Delivery and Cancer Treatment. www.Vanderbilt.edu accessed on 20.12.2011.

15. Shankar S, Vavia PR, Francesco T, Satyen T. Formulation of Betacyclodextrin based nanosponges of Itraconazole. J Incl Phenom Macrocycl Chem, 2007; 57: 89-94.

16. Lala R, Thorat A, Gargote C. Current trends in $\beta$ cyclodextrin based drug delivery systems. Int $\mathrm{J}$ Res Ayur Pharm, 2011; 2(5): 1520-1526.

17. Isabelle A, Christine V, Helene C, Elias F, Patrick C. Spongelike Alginate Nanoparticles as a new potential system for the delivery of Antisense Oligonucleotides. Antisense and Nucleic Acid Drug Development, 1999; 9(3): 301-312.

18. Gilardi G, Trota F, Cavalli R, Ferruti P, Ranucci E, Di Nardo G, Roggero C, Tumiatti V. Cyclodextrin nanosponges as carrier for biocatalysts, and in the delivery and release of enzymes, proteins, vaccines and antibodies. WO2009149883 A1; 2009.

19. Trotta F, Tumiatti W. Cross-linked polymers based on cyclodextrins for removing polluting agents. WO 03/085002 A1; 2003.

20. Wong VN, Fernando G, Wagner AR, Zhang J, Kinsel GR, Zauscher S, Dyer DJ. Separation of peptides with polyionic nanosponges for MALDIMS analysis. Langmuir, 2009; 25(3):1459-65.

21. Cavalli R, Akhter AK, Bisazza A, Giustetto P, Trotta F, Vavia P. Nanosponge formulations as oxygen delivery systems. Int J Pharm, 2010; 402(1-2):254-257.

22. Longo C, Gambara G, Espina V, Luchini A, Bishop B, Patanarut AS, Petricoin EF 3rd, Beretti 
F, Ferrari B, Garaci E, De Pol A, Pellacani G, Liotta LA. A novel biomarker harvesting nanotechnology identifies Bak as a candidate melanoma biomarker in serum. Exp Dermatol. 2011; 20(1):29-34.

23. Amber V, Shailendra S, Swarnalatha S. Cyclodextrin based novel drug delivery systems. J Incl Phenom Macrocycl Chem, 2008; 62:23-42.

24. Rajeswari C, Alka A, Javed A, Khar R K. Cyclodextrins in drug delivery: an update review. AAPS pharmSciTech, 2005; 6(2):E329-E357.

25. Ramnik S, Nitin B, Jyotsana M, Horemat SN. Characterization of Cyclodextrin Inclusion complexes -A Review. J Pharm Sci Tech, 2010; 2(3):171-183.

26. Ralph JP, Daniel ES, Alice EV. Targeted nanoparticles that deliver a sustained, specific srelease of Paclitaxel to Irradiated tumors. Cancer Res, 2010; 70:4550-4559.

27. Roberta C, Francesco T, Wander T. Cyclodextrinbased nanosponges for drug delivery. $\mathrm{J}$ Incl Phenom Macrocycl Chem, 2006; 56: 209-213.

28. Trotta F, Cavalli R. Characterization and application of new hyper-cross-linked cyclodextrins. Compos Interface, 2009; 16: 39-48.

29. Millan R, Diaz A, Mohallem N, Process of composites preparation between particulate materials and cyclodextrins and their derivatives products thereof. WO 03/041095; 2003.

30. Francesco T. Cyclodextrin nanosponges: a new material in supramolecular chemistry Inorganic, Physical and Materials Chemistry Department, University of Torino-an Abstract.

31. Ferruti P, Ranucci F, Trotta F, Cavalli R, Fernandez C. Hyperbranched polymers based on cyclodextrins and Poly(amidoamines) for the controlled release of insoluble drugs WO2008/151775 A2; 2008.

32. Vavia PR, Swaminattan S, Trota F, Cavalli R. Applications of Nanosponges in Drug Delivery XIII International Cyclodextrin Symposium, Turin 14-17, May 2006.

33. Thorstenin L, Dominique D. Cyclodextrins and their pharmaceutical applications. int $\mathrm{j}$ pharm, 2007; 329:1-11.

34. Thorstenin L, Marcus EB. Pharmaceutical applications of Cyclodextrins. 1.Drug solubilization and stabilization. J.Pharm.Sci, 1996; 85(10):1017-1025.

35. Roger AR, valentine JS. Pharmaceutical applications of Cyclodextrins. 2. In Vivo Drug Delivery. J.Pharm.Sci, 1996; 85(11):1142-1169.

36. Prof. Eva Harth, Nanosponges as Synergistic Drug Delivery Systems to Increase the Efficacy of Treatment. Department of Chemistry, Vanderbilt University, USA.2011.

37. Ludovica S, Katia M, Marco D, Carlo R, Francesco T, Valentina S. $\beta$-Cyclodextrin-based nanosponges as carriers for 1-MCP in extending the postharvest longevity of carnation cut flowers: an evaluation of different degrees of cross-linking. Plant Growth Regul, 2011; 65:505-511.

38. Trotta F, Dolci M, Devecchi M, Scariot V, Seglie L. Nanosponges as potential carriers to increase the flowers' vaselife. National Cyclodextrin Symposium, Asti, Italy, 2007.

39. Declan F, Santosh Y, Shanti S. Silicon Nanosponge Particles US7569202; 2009.

40. Lu Z, Cheng Bo, Hu Yeli, Zhang Youhoung, Zou Guolin. Complexation of resveratrol with cyclodextrins: solubility and antioxidant activity. Food Chemistry, 2009; 113(1):17-20.

41. Lucas-Abellán C, Fortea I, López-Nicolás JM, Núñez-Delicado E. Cyclodextrins as resveratrol carrier system. Food Chemistry, 2007; 104(1):39 44.

42. Szejtli, J. Introduction and general overview of cyclodextrin chemistry. Chem. Rev, 1998; 98:1743-1754.

43. Peeters, J., et al. Characterization of the interaction of 2- hydroxypropyl- $\beta$-cyclodextrin with itraconazole at $\mathrm{pH} \mathrm{2,} 4$ \&7. J Pharm Sci, 2002; 91(6): 1414-1422.

44. Erem Bilensoy Cyclodextrins in Pharmaceutics, Cosmetics, and Biomedicine: Current and future industrial applications. John Wiley \& Sons, Inc. 2011.

45. Seglie L, Martina K, Devecchi M, Roggero C, Trotta F, Scariot V. The effects of $1-\mathrm{MCP}$ in cyclodextrin-based nanosponges to improve the vase life of Dianthus caryophyllus cut flowers. Postharvest Biol Technol, 2011; 59:200-205.

46. Seiler M. Hyperbranched polymers: phase behavior and new applications in the field of chemical engineering. Fluid Phase Eq, 2006; 241:155-174

47. Eva Harth, Nanomedicine: Development of "Nanosponges" as superior sustain delivery systems of diverse biological cargos. Department of Chemistry, Vanderbilt University, USA, 2011.

48. Edward $\mathrm{CH}$, Characterisation of Nano-Porous Silicon Particles, Department of Manufacturing and Operations Engineering and Materials and Surface Science Institute, University of Limerick, Ireland, 2010.

49. Edward Chadwick and David A. Tanner. Characterisation of Porous Silicon Nanosponge Particles. Department of Manufacturing and Operations Engineering and Materials and Surface Science Institute, University of Limerick, Ireland, 2010.

50. Nilesh J, Ruchi J, Navneet T, Brham P, Gupta, Deepak K, Jeetendra B, Surendra J. Nanotechnology: A Safe And Effective Drug Delivery System. Asian J Phar Cli Res, 2010; 3(3): 159-165.

51. Andrea $M$, Franca $C$, Luciana $M$, Fabio $G$, Giuseppina R, Francesco T, Barbara R, Aldo F, Giovanni G. HR MAS NMR, powder XRD and raman spectroscopy study of inclusion phenomena 
in $\beta C D$ nanosponges. $\mathrm{J}$ Incl Phenom Macrocycl Chem, 2011; 69:403-409.

52. DeQuan L, Min M. Nanosponges for water purification. Clean products and processes, 2000; 2: 112-116.

53. Arkas M, Allabashi R, Tsiourvas D, Mattausch EM, Perfler R. Organic/inorganic hybrid filters based on dendritic and cyclodextrin "nanosponges" for the removal of organic pollutants from water. Environ Sci Technol, 2006; 40(8):2771-2777.

54. Di Nardo G, Roggero C, Campolongo S, Valetti F, Trotta F, Gilardi G. Catalytic properties of catechol 1,2-dioxygenase from Acinetobacter radioresistens $\mathrm{S} 13$ immobilized on nanosponges. Dalton Trans, 2009; 33:6507-6512.

55. Duchene D, Vaution C, Glomot F. Cyclodextrin, Their Value in pharmaceutical Technology. Drug Dev Ind Pharm, 1998; 12(11-13): 2193-2215.

56. Marzouqi A.H.A, Shehatta I, Jobe B, Dowaidar A. Phase solubility and inclusion complex of Itraconazole with $\quad$-cyclodextrin using supercritical carbon dioxide. J Pharm Sci, 2006; 95(2): 292-304.

57. Tayade PT, Vavia PP. Inclusion complexes of Ketoprofen with $\beta$ - cyclodextrins: Oral pharmacokinetics of Ketoprofen in human. Indian J Pharm Sci, 2006; 68(2):164-170.

58. Noriaki F, Seiji I, Saburo N. Advances in physical chemistry and pharmaceutical applications of cyclodextrins. Pure Appl Chem, 2008; 80(7):1511-1524.

59. Arun R, Ashokkumar CK, Sravanthi VVNSS. Cyclodextrins as drug carrier Molecule: A Review. Sci Pharm, 2008; 76: 567-598.

60. Mark ED, Marcus EB. Cyclodextrin-based Pharmaceutics: past, present and future. Drug Discovery, 2004; 3:1023-1035.
61. Mei D, Xu X, Jia S, Shaozhi F, MaLing G, Feng L, ZhiYong Q. Preparation of camptothecinloaded PCEC microspheres for the treatment of colorectal peritoneal carcinomatosis and tumor growth in mice. J canlet, 2011; 312:189-196.

62. Amri A, Chaumeil JC, Sfar S, Charrueau C. Administration of resveratrol: what formulation solutions to bioavailability limitations?.J Control release, 2011; 09(083):1-12.

63. Srikanth MV, Muralimohanbabu GV, Sreenivasa rao N, Sunil SA, Balaji S, Ramanamurthy KV. Dissolution rate enhancement of poorly soluble bicalutamide using $\beta$-cyclodextrin inclusion complexation. Int J Pharm Ph Sci, 2010; 2(1): 191-198.

64. James B, Stefan P. Some important considerations in the use of cyclodextrins. Pharm res, 1999; 16(12):1796-1798.

65. Thorstein L, RobertO F. cyclodextrins in solid dosage forms. Faculty of Pharmacy, University of Iceland, and Senior Partner, Strategic Business Solutions.

66. Abd-Elgawad R, Shimaa E. Electrochemistry of Cyclodextrin Inclusion Complexes of Pharmaceutical Compounds The Open Chemical and Biomedical Methods Journal, 2010; 3: 74-85

67. Gharib Naseri N, Ashnagar A, Husseini F. Study of the Inclusion Complexation of Piroxicam- $\beta$ Cyclodextrin and Determination of the Stability Constant (K) by UV-Visible Spectroscopy. Scientia Iranica, 2007; 14(4): 308-315

68. Narender Reddy M, Rehana T, Ramakrishna S, Chowdary KPR, Prakash VD. $\beta$-Cyclodextrin Complexes of Celecoxib: Molecular-Modeling, Characterization, and Dissolution Studies. AAPS PharmSci, 2004; 6(1): 1-9. 